\title{
Symmetrical Slot on C-Shape Microstrip Patch for Tri-band Application
}

\author{
Madhavi Bagal \\ M. S. Bidwe Collage of Engineering, \\ Latur
}

\author{
S.S. Killarikar \\ M. S. Bidwe Collage of Engineering, \\ Latur
}

\begin{abstract}
A new triple band microstrip patch antenna is presented in this paper for wireless communication. By adjusting the dimension of ground plane and patch, its fractional bandwidth at primary resonance mode can increased sufficiently to achieve desired bandwidth of proposed antenna. In proposed design, it has been found that the symmetrical position of patch over ground plane have clear impact on overall antenna performance. Many antenna structures have been modeled to demonstrate the effects of these parameters on the resulting triple band response. We design antenna for $(1.07-1.75 \mathrm{GHz})$, (3.22-4.35) and (5.78-6.5GHz).
\end{abstract}

\section{Keywords}

Microstrip antenna, Dielectric Patch antenna, Length; Losses; strip width; strip length.

\section{INTRODUCTION}

Ahmed H. Reja [1] proposed Study of Micro Strip Feed Line Patch Antenna experimentally increase the Return Loss $33.60 \mathrm{~dB}$ at $2.5 \mathrm{GHz}$ frequency and VSWR is 1.5 by using CAD for RT DUROID 5880. Santanu Kumar Behera and Y. Choukiker [2] proposed Design and Optimization of Dual Band Micro Strip Antenna using Practical Swarm Optimization maximize the return loss for dual band Frequency at $2.4 \mathrm{GHz}$ is $-43.9 \mathrm{~dB}$ and at $3.08 \mathrm{GHz}$ is $-27.4 \mathrm{~dB}$. M. A. S. Alkanhal[3] proposed microstrip antenna by integrating various shapes to get reduced size and maintain performance of antenna for triple band. A A Deshmukh and G Kumar [4] proposed compact L-Shape patch broadband Microstrip antenna experimentally increase bandwidth up to 13.7\%. Z M Chen [5] further increase bandwidth of this antenna up to $23.7 \%-24.43 \%$. K F Lee [6] proposed U Shape slot shorting post small size Microstrip Antenna and increase bandwidth up to $42 \%$. S C Gao [7] used uniplanar photonic band gap structure for enhancing band width and gain. M Khodier [8] New wideband stacked microstrip antennas for enhancing band width. Major issue for micro strip antenna is narrow Bandwidth. Asymmetrical patch on ground plane affect overall performance of antenna. $\mathrm{K}$. Song et. al [10] designed asymmetrical L-shaped patch antenna for UWB application with $-10 \mathrm{~dB}$ return loss and peak gain 2.22 to $6.1 \mathrm{dBi}$ for operating bandwidth 3.01-11.30 $\mathrm{GHz}$ frequency.

In this paper we tested our design by using electromagnetic simulator HFSS. Researchers are focusing on how to design microstrip antennas for various band. Due to its advantages such as low-cost, small size low weight and capability to integrate with Microwave integrated circuits, the microstrip patch antenna is a very good candidate for integrations in applications such as wireless communication systems, mobile phones and laptops. In this paper a single C-slot microstrip antenna with two symmetrical strip (Figure 1) is designed and simulated for the frequency range of 0.5-7 GHz. This antenna presents an extension to the single $\mathrm{C}$-slot antenna presented at LAPC $2009[8,9]$. The proposed antenna has a gain of 3.8 $\mathrm{dBi}$ and presents a size reduction of $33 \%$ when compared to a conventional square microstrip patch antenna. Extensive simulation results using Advanced Design Systems by Agilent (uses the MOM method) will be presented.

\section{PROPOSED DESIGN}

The results of proposed triple band microstrip patch antenna verified in HFSS Simulator with optimization. The initial antenna is shown in Figure 1 and Figure 2. It consists of a single c-slot with two slot symmetrical to c-slot at the center of patch. Each end and placed within the patch [7]. The resulting antenna structure has the following parameters; the patch shape length $\mathrm{W}_{\mathrm{p}}=28.5 \mathrm{~mm}$, and its width $\mathrm{L}_{\mathrm{p}}=24.5 \mathrm{~mm}$. The size of the ground plane has been found to be of $\mathrm{L}_{\mathrm{g} 1}=$ $40 \mathrm{~mm}$ and $\mathrm{W}_{\mathrm{g} 1}=40 \mathrm{~mm}$. The height of substrate is $\mathrm{h}=1.5 \mathrm{~mm}$ and dielectric constant $\varepsilon_{\mathrm{r}}=4.4$. A $50 \Omega$ inset microstripline feed is attached to the microstrip and has a width $\mathrm{L}_{\mathrm{t}}=2.6 \mathrm{~mm}$ and length $\mathrm{W}_{\mathrm{t}}=54 \mathrm{~mm}$. The length and width of c-slot that is $\mathrm{S}_{3}$ is $21 \mathrm{~mm}$ and $1 \mathrm{~mm}$ respectively.

We will conduct a simulation study on the structure of Figure 1 by adjusting the dimension of slot placed above and below of c-shape slot that is $S_{1}$ and $S_{2}$. The resulting dimension of slot $S_{1}$ and $S_{2}$ after simulation antenna structure are $1.5 \mathrm{~mm} \times 21$ and $2 \mathrm{~mm} \times 21 \mathrm{~mm}$ respectively. Initially we put ground position for entire patch. As we reduce ground material, it is found that return loss is getting reduced from $9 \mathrm{~dB}$ to $-15 \mathrm{~dB}$. The ground substrate length on backside of patch is reduced and simulated for different dimension; it is observed that we get second (3.22-4.35 GHz) and third band $(5.78-6.5 \mathrm{GHz})$ with sufficient return loss, the resulting return loss responses obtained by reducing ground plane, we obtain optimized return loss as presented in figure 3. Further we simulated for different dimension of ground plane that is ground plane at front side of patch. Again we simulated for different dimension of ground plane to get optimized result, in this case it observed that we get first, second and third band with sufficient return loss, the resulting return loss presented in figure 4 and figure 5. From above result the finalized dimension of ground plane are, dimension of backside and front side ground plane are $40 \mathrm{~mm} \times 43 \mathrm{~mm}, 14 \mathrm{~mm} \times 36 \mathrm{~mm}$ respectively.

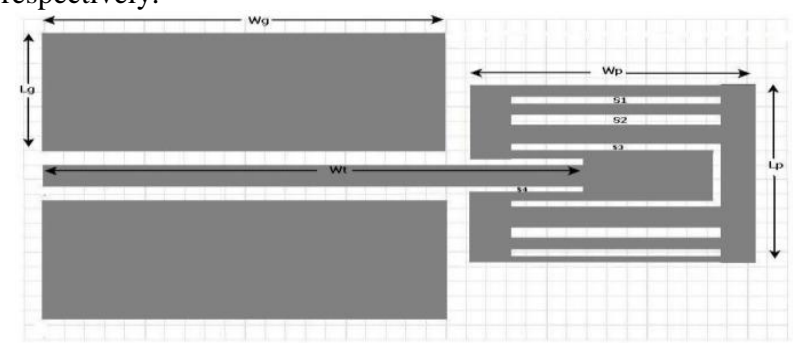

Figure 1. Proposed antenna design (Front side) 


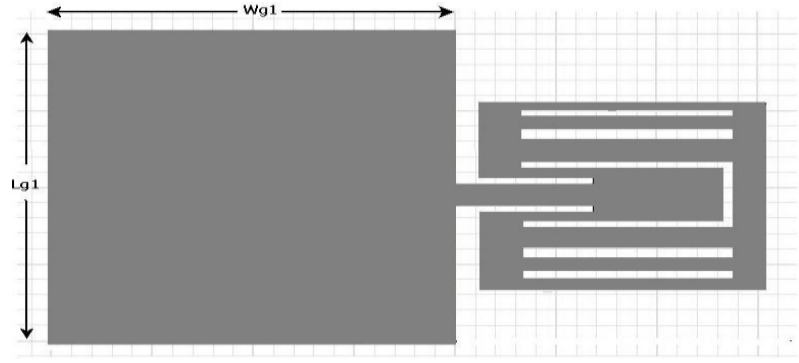

Figure 1. Proposed antenna design (Back side)

From figure 4 and figure 5 , it is observed that, we get minimum return loss that is $-45 \mathrm{~dB},-25 \mathrm{~dB}$ and $-35 \mathrm{~dB}$ at $1.5 \mathrm{GHz}, 3.9 \mathrm{GHz}$ and $5.9 \mathrm{GHz}$ respectively.

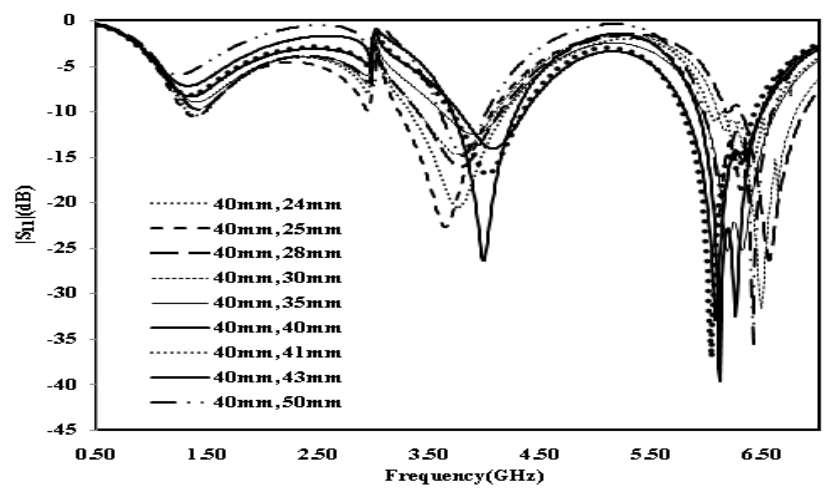

Fig 3: Return loss of antenna for variation in ground plane (backside)

Results of the variation of the size of the ground plane, as Figure 1 implies, that the tripple band response deteriorates for ground plane width other than the reference value.

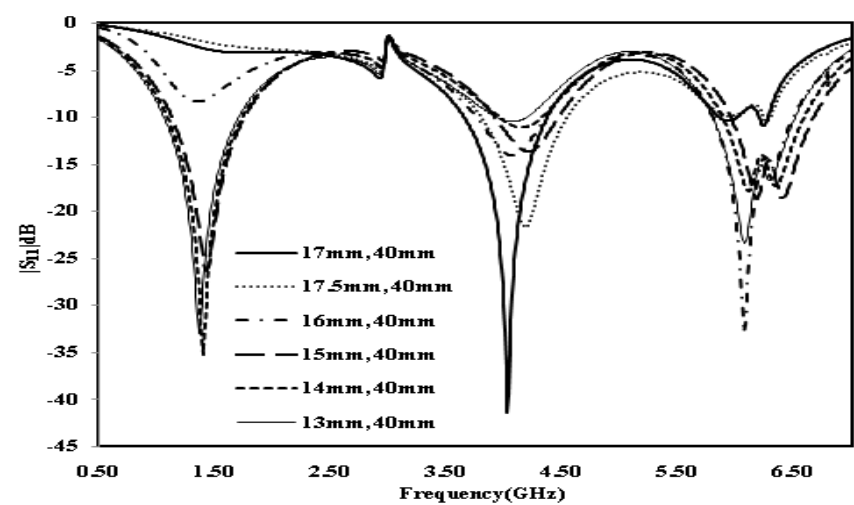

Fig 4: Return loss of antenna for variation in ground plane (frontside)

However, tripple-band responses are obtained with increased or decreased higher resonating bands. The effect of the width of ground has been demonstrated in Figure 3, Figure 4 and Figure 5. For larger values of the width of ground, the antenna offers a one-band resonant behavior, and the tripleband resonance occurs as the width is made smaller and approaches that of the reference antenna.

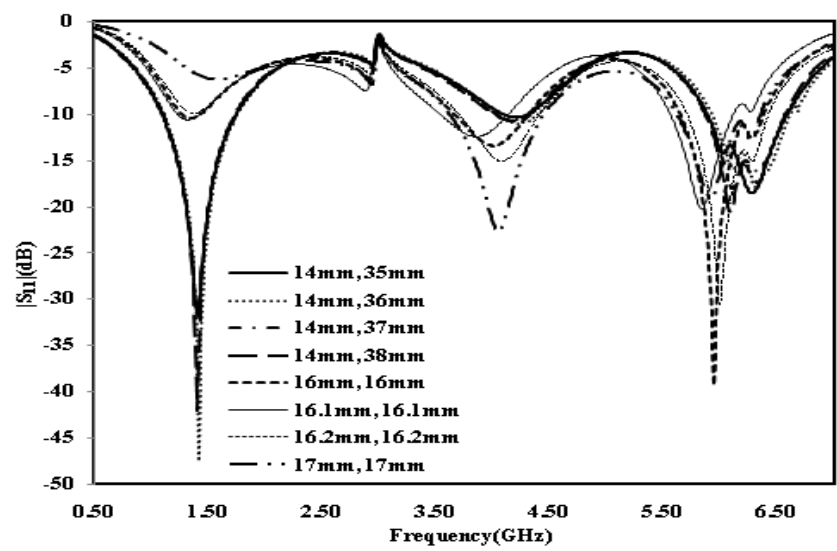

Fig 5: Return loss of antenna for variation in ground plane (frontside)

Figure 6 depicts the radiation pattern for first band that is $1.5 \mathrm{GHz}$ frequency since return loss at this frequency is $-45 \mathrm{~dB}$. Similarly Figure 7 presents radiation pattern for second band that is $3.9 \mathrm{GHz}$ since the return loss at this frequency. The current distribution for is also presented in figure 3 that is the resulting current distribution for second band that is at 1.5 $\mathrm{GHz}$ since return loss at this frequency is -10.04 . Gain of antenna at $2.4 \mathrm{GHz}$ is $4 \mathrm{dBi}$ and radiation pattern of antenna as presented in figure 4 and figure 5 respectively.

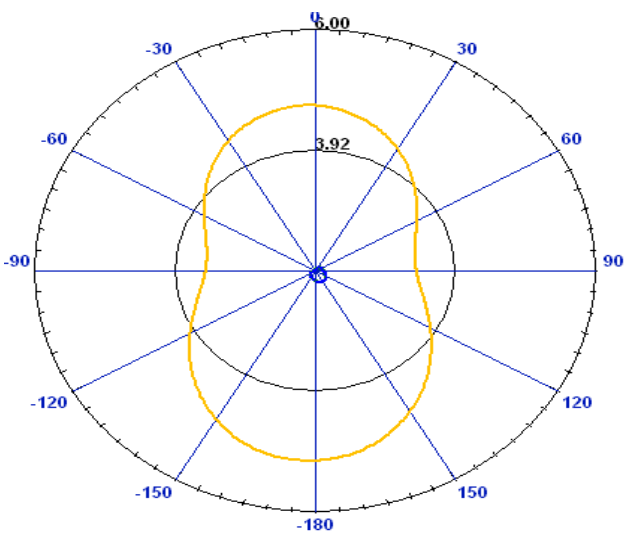

Fig 6: Radiation pattern at $1.5 \mathrm{GHz}$

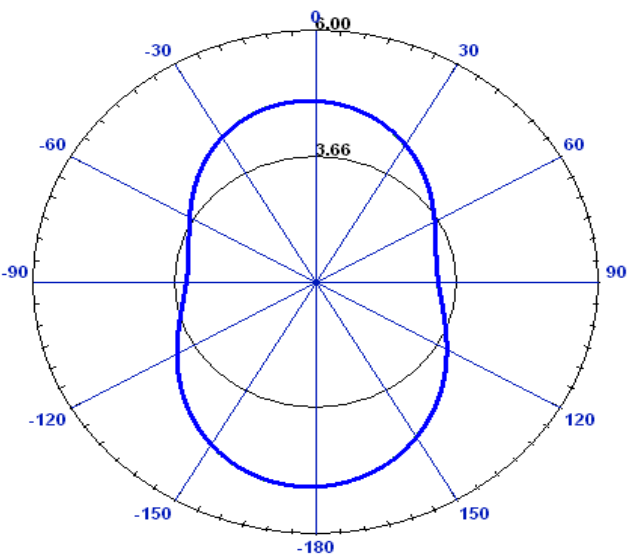

Fig 7: Radiation pattrn at $3.9 \mathrm{GHz}$

\section{CONCLUSION}

The design optimization of a dual slot patch antenna has been presented and discussed. It has been shown that with correct selection of slot dimensions on patch and shape of ground plane, a triple band frequency response can be achieved. With 
this antenna, we get much improved bandwidth this design is obtained method, as a candidate for use for triple band that is $(1.07-1.75 \mathrm{GHz}),(3.22-4.35 \mathrm{GHz})$ and $(5.78-6.5 \mathrm{GHz})$. The antenna has been modeled and its performance has been analyzed using a HFSS simulator. The proposed antenna has been found to possess a miniaturized size and a width making it suitable for compact size triple band applications. The simulated results of HFSS at $1.5 \mathrm{GHz}$ is Return loss $=-45 \mathrm{~dB}$, at $3.9 \mathrm{GHz}$ Return loss $=-25 \mathrm{~dB}$ and at $5.9 \mathrm{GHz}$ Return loss $=$ -35 . VSWR at $1.5 \mathrm{GHz}$ is 2.01 , Gain $=3.4 \mathrm{dBi}$ at $1.9 \mathrm{GHz}$ Efficiency $=90 \%$.

\section{REFERENCES}

[1] Ahmed H. Reja "Study of Micro Strip Feed Line Patch Antenna", Antennas and Propagation International Symposium, vol. 27, pp. 340-342 December 2008. .

[2] Sahntanu Kumar Behera and Y. Choukiker, "Design and Optimization of Dual Band Micro Strip Antenna Using Practicle Swarm Optimization Technique," Springer Science Business Media, LLC, pp. 1346-1354, 2010

[3] M. A. S. Alkanhal, "Compact composite triple band antenna", Progress In Electromagnetics Research, PIER 93, 221-236, 2009

[4] A. A. Deshmukh and G. Kumar, "Compact broadband gap-coupled shorted L-shaped microstrip antennas," IEEE Antennas and Propagation International Symposium, vol 1, (Baltimore, Maryland), pp. 106-109, IEEE, July 2001

[5] Z. M.Chen and Y. W. M. Chial, "Broadband probe-fed L-shaped plate antenna," Microwave and Optical Technology Letters, vol. 26, pp. 204-206, 1985.

[6] K. F. Lee, K. M. Luk, K. F. Tong, Y. L. Yung, and T. Huynh, "Experimental study of the rectangular patch with a U-shaped slot," IEEE Antennas and Propagation International Symposium, vol.1, (Baltimore, Maryland), pp. 10-13, IEEE, July 1996.
[7] S. C. Gao, L. W. Li, M. S. Leong, and T. S. Yeo, "Design and analysis of a novel wideband microstrip antenna," IEEE Antennas and Propagation International Symposium,vol.1, (Boston, Massachusetts), pp. 90-93, IEEE, July 2001.

[8] M. Khodier and C. Christodoulou, "A technique to further increase the bandwidth Of stacked microstrip antennas," IEEE Antennas and Propagation International Symposium, vol. 3, pp. 1394-1397, IEEE, July 2000.

[9] Neenansha Jain, Anubhuti Khare, Rajesh Nema, "EShape Micro strip Patch Antenna on Different Thickness for pervasive Wireless Communication", International Journal of Advanced Computer Science and Applications, Vol. 2, No. 4, 2011

[10] K. Song, Y.-Z. Yin, S.-T. Fan, and B. Chen," compact open ended L-shaped slot antenna with asymmetrical rectangle patch for UWB application", Progress In Electromagnetics Research C, Vol. 19, 235-243, 2011.

\section{AUTHOR PROFILE}

Madhavi Bagal is persuing Master of Engineering in Electronics and communication from M. S. Bidwe College of Engineering Latur. She has received B. E. in Electronics and communication from M. S. Bidwe College of Engineering Latur. She is currently working as lecturer in VDF School of polytechnic Latur, India. Her research area is antenna design.

S. S. Killarikar is currently Associate Professor in the Department of Electronics and communication with 25 Years of teaching experience at M. S. Bidwe College of Engineering Latur. She has received Master of Engineering in Electronics from S.G.G.S. Nanded, India. Her area of Specialization is Computer Technology. 